\title{
A Novel and Simple Maximum Available Gain Equalization Technique for Microwave Amplifiers
}

\author{
C. de la Morena-Álvarez-Palencia*, M. Burgos-García and F. Pérez-Martínez
}

Department of Signals, Systems and Radiocommunications, Polytechnical University of Madrid, Spain

\begin{abstract}
A novel method to equalize the maximum available gain (MAG) is presented. The method is based on the introduction of a simple interstage network between two transistors, where the set is treated as a single element. The technique provides not only excellent gain flatness but also two additional advantages relative to conventional designs: simpler matching networks and smaller size. The method is simple, and the design is easy. A high gain L-band amplifier prototype has been developed to verify the equalization technique, achieving a few hundredths of dB gain flatness variation over the operation bandwidth.
\end{abstract}

\section{INTRODUCTION}

In the last several years, radio communications systems have progressively increased their bit rates, and they have started to use more and more complex modulation formats in order to achieve high spectral efficiency and noise immunity. These modulation schemes are usually very sensitive to linear distortion, so high quality radio stages are necessary.

The amplification stages are usually one of the main problems for applications that require strict flatness specifications. The maximum available gain (MAG) of a typical transistor decreases with the square of frequency $(6 \mathrm{~dB} /$ octave) [1]. Therefore, it is necessary to find a way to compensate for transistor rolloff.

A standard solution consists of designing matching networks as lossless equalizers in order to simultaneously provide impedance matching and the appropriate gain versus frequency compensation required for the transistor [2-4]. For high power amplifiers, where considerations of efficiency and power output are critical, only the input matching network is used to compensate for the inherent gain rolloff of the high power transistors. Another traditional equalization method, applicable to cascaded amplifiers, is based on the synthesis of interstage networks with a complementary characteristic to the transistors rolloff [5]. Both methods, which can be combined in order to improve the equalization performance, are widely used in most microwave amplifiers, especially for broad band applications.

The equalizers can be made with lumped elements or transmission-line sections. Lumped elements have poor quality factor and thermal stability, which are limited by the inductors and capacitors, respectively [6]. The use of lumped components is problematic for low loss or narrowband applications due to the heavy impact of parasitics. There is no escaping the use of larger distributed elements, such as transmission-line sections, when insertion loss and power

*Address correspondence to this author at the Department of Signals, Systems and Radiocommunications, Polytechnical University of Madrid, Spain; Fax: (+34)913367362; Tel: (+34)913367358;

E-mail: cmorena@gmr.ssr.upm.es handling are of a major concern [7]. The low microwave frequency range between 1 and $3 \mathrm{GHz}$ is especially problematic. These frequencies are not high enough to require a fully distributed design, while lumped designs are limited by decreasing component performance and board parasitics.

As a solution, we propose a MAG equalization technique applicable to two-state microwave amplifiers. The transistors rolloff compensation is achieved by means of a simple interstage network. While classical methods lead to bigger and more complex structures, with the technological problems mentioned above, this technique provides an easy and compact solution. The design is straightforward and the results show excellent performance.

The technique has been verified by means of a high gain L-band amplifier belonging to the Communication, Ocean and Meteorological Satellite (COMS) [8].

\section{TECHNIQUE}

In this letter, we present a new method to equalize the microwave amplifier MAG within a bandwidth $B W=f_{2}-f_{1}$, where $f_{1}$ and $f_{2}$ are the lower and upper frequencies of the operation bandwidth, respectively. The proposed structure is based on the introduction of an interstage network between two transistors, consisting of a transmission line with electrical length $\theta$, and characteristic impedance $Z_{\mathrm{o}}$. The suggested structure is shown in Fig. (1).

$S^{A}$ and $S^{C}$ represent the transistors' scattering matrixes, and $S^{B}$ is the transmission line scattering matrix, all relative to $\mathrm{Z}_{0}$. That is:

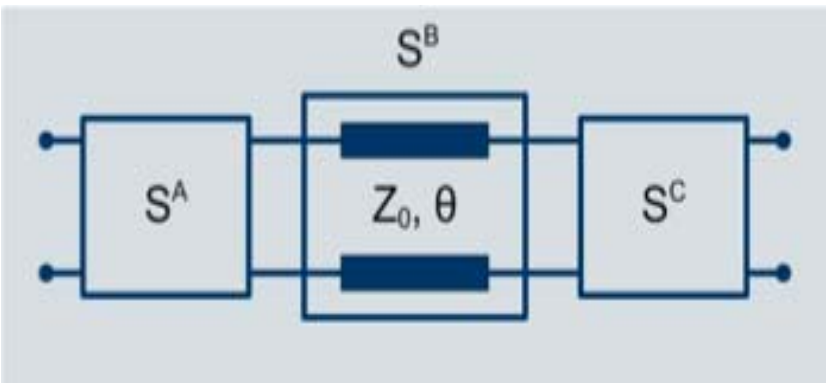

Fig. (1). Equalization structure. 


$$
\begin{aligned}
& \mathrm{S}^{\mathrm{A}}=\left(\begin{array}{cc}
\mathrm{s}_{11}^{\mathrm{A}} & \mathrm{s}_{12}^{\mathrm{A}} \\
\mathrm{s}_{21}^{\mathrm{A}} & \mathrm{s}_{22}^{\mathrm{A}}
\end{array}\right) \\
& \mathrm{S}^{\mathrm{B}}=\left(\begin{array}{cc}
0 & \mathrm{e}^{-\mathrm{j} \theta} \\
\mathrm{e}^{-\mathrm{j} \theta} & 0
\end{array}\right) \\
& \mathrm{S}^{\mathrm{C}}=\left(\begin{array}{cc}
\mathrm{s}_{11}^{\mathrm{C}} & \mathrm{s}_{12}^{\mathrm{C}} \\
\mathrm{s}_{21}^{\mathrm{C}} & \mathrm{s}_{22}^{\mathrm{C}}
\end{array}\right)
\end{aligned}
$$

The overall scattering matrix, calculated as a cascade of three two-port networks, can be expressed as follows:

$$
\mathrm{S}=\left(\begin{array}{cc}
\mathrm{s}_{11}^{\mathrm{A}}+\frac{\mathrm{s}_{12}^{\mathrm{A}} \cdot \mathrm{s}_{21}^{\mathrm{A}} \cdot \mathrm{s}_{11}^{\mathrm{C}} \cdot \mathrm{e}^{-\mathrm{j} 2 \theta}}{1-\mathrm{s}_{22}^{\mathrm{A}} \cdot \mathrm{s}_{11}^{\mathrm{C}} \cdot \mathrm{e}^{-\mathrm{j} 2 \theta}} & \frac{\mathrm{s}_{12}^{\mathrm{A}} \cdot \mathrm{s}_{12}^{\mathrm{C}} \cdot \mathrm{e}^{-\mathrm{j} \theta}}{1-\mathrm{s}_{22}^{\mathrm{A}} \cdot \mathrm{s}_{11}^{\mathrm{C}} \cdot \mathrm{e}^{-\mathrm{j} 2 \theta}} \\
\frac{\mathrm{s}_{21}^{\mathrm{A}} \cdot \mathrm{s}_{21}^{\mathrm{C}} \cdot \mathrm{e}^{-\mathrm{j} \theta}}{1-\mathrm{s}_{22}^{\mathrm{A}} \cdot \mathrm{s}_{11}^{\mathrm{C}} \cdot \mathrm{e}^{-\mathrm{j} 2 \theta}} & \mathrm{s}_{22}^{\mathrm{C}}+\frac{\mathrm{s}_{12}^{\mathrm{C}} \cdot \mathrm{s}_{21}^{\mathrm{C}} \cdot \mathrm{s}_{22}^{\mathrm{A}} \cdot \mathrm{e}^{-\mathrm{j} 2 \theta}}{1-\mathrm{s}_{22}^{\mathrm{A}} \cdot \mathrm{s}_{11}^{\mathrm{C}} \cdot \mathrm{e}^{-\mathrm{j} 2 \theta}}
\end{array}\right)
$$

The MAG, defined as the transduction gain when there are simultaneous input and output conjugate match conditions, is given by [9]:

$$
\text { MAG }=\frac{\left|\mathrm{s}_{21}\right|}{\left|\mathrm{s}_{12}\right|}\left(\mathrm{k}-\sqrt{\mathrm{k}^{2}-1}\right)
$$

where $k$ the Rollet stability factor

$$
\mathrm{k}=\frac{1-\left|\mathrm{s}_{11}\right|^{2}-\left|\mathrm{s}_{22}\right|^{2}+\left|\mathrm{s}_{11} \cdot \mathrm{s}_{22}-\mathrm{s}_{12} \cdot \mathrm{s}_{21}\right|}{2 \cdot\left|\mathrm{s}_{12} \cdot \mathrm{s}_{21}\right|}
$$

MAG exists only in a case of unconditional stability, that is, when the following necessary and sufficient conditions are met:

$$
\left\{\begin{array}{l}
\mathrm{k} \geq 1 \\
\left|\mathrm{~s}_{11} \cdot \mathrm{s}_{22}-\mathrm{s}_{12} \cdot \mathrm{s}_{21}\right| \leq 1
\end{array}\right.
$$

In many cases, the active devices can be assumed to be unilateral; that is, $\left|s_{12}\right|$ is small enough to be ignored. The error in the transducer gain caused by approximating $\left|s_{12}\right|$ to be zero is given by the ratio $e$ :

$$
\frac{1}{(1+u)^{2}}<\mathrm{e}<\frac{1}{(1-u)^{2}}
$$

where $\mathrm{u}$ is defined as the unilateral figure of merit,

$$
\mathrm{u}=\frac{\left|\mathrm{s}_{12}\right| \cdot\left|\mathrm{s}_{21}\right| \cdot\left|\mathrm{s}_{11}\right| \cdot\left|\mathrm{s}_{22}\right|}{\left(1-\left|\mathrm{s}_{11}\right|^{2}\right) \cdot\left(1-\left|\mathrm{s}_{22}\right|^{2}\right)}
$$

The unilateral assumption is justified by an error of a few tenths of a $\mathrm{dB}$ or less. We will suppose the devices are unilateral at the outset, so $\left|\mathrm{s}_{12}{ }^{\mathrm{A}}\right|$ and $\left|\mathrm{s}_{12}{ }^{\mathrm{C}}\right|$ will be considered null. According to (4), as $\left|s_{12}{ }^{A}\right|$ and $\left|s_{12}{ }^{C}\right|$ are multiplying the overall $s_{12}$ numerator, $\left|s_{12}\right|$ will be also null, and the MAG will reduce to the unilateral case [9]:
$M A G_{u}=\frac{\left|s_{21}\right|^{2}}{\left(1-\left|s_{11}\right|^{2}\right) \cdot\left(1-\left|s_{22}\right|^{2}\right)}$

For the same reason, the second terms in both $s_{11}$ and $s_{22}$ can be neglected so that $M A G_{u}$ will be:

$\mathrm{MAG}_{\mathrm{u}} \approx \frac{\left|\mathrm{s}_{21}\right|^{2}}{\left(1-\left|\mathrm{s}_{11}^{\mathrm{A}}\right|^{2}\right) \cdot\left(1-\left|\mathrm{s}_{22}^{\mathrm{C}}\right|^{2}\right)}$

The $\left|s_{21}\right|^{2}$ term will have a stronger influence on (11) than the denominator. Thus, we will try to achieve MAG flatness by means of equalizing the $s_{21}$ module, given by:

$$
\left|\mathrm{s}_{21}\right|=\frac{\left|\mathrm{s}_{21}^{\mathrm{A}} \cdot \mathrm{s}_{21}^{\mathrm{C}}\right|}{\left|1-\mathrm{s}_{22}^{\mathrm{A}} \cdot \mathrm{s}_{11}^{\mathrm{C}} \cdot \mathrm{e}^{-\mathrm{j} 2 \theta}\right|}
$$

The electrical length $\theta$ characterizes the effect of the transmission line. In microstrip technology, this electrical length is expressed as follows:

$\theta=\frac{2 \pi \sqrt{\varepsilon_{\text {eff }}} \cdot \mathrm{f}}{\mathrm{c}} \mathrm{l}$

where $\varepsilon_{\text {eff }}$ corresponds to the effective dielectric constant of the transmission line, $f$ is the operation frequency, $c$ is the speed of light in free space, and $l$ is the transmission line physical length.

In transistors, both the phase and module of $s_{21}$ decrease with increasing frequency. However, the $s_{11}$ and $s_{22}$ parameters vary more slowly. Note that the denominator of $s_{12}$ depends on $\mathrm{s}_{22}{ }^{\mathrm{A}}, \mathrm{s}_{11}{ }^{\mathrm{C}}$ and $\mathrm{e}^{-\mathrm{j} 2 \theta}$. As $\mathrm{s}_{22}{ }^{\mathrm{A}}$ and $\mathrm{s}_{11}{ }^{\mathrm{C}}$ vary more slowly with frequency than the exponential, we can approximate that $\mathrm{s}_{22}{ }^{\mathrm{A}} \cdot \mathrm{s}_{11}{ }^{\mathrm{C}}$ is a constant within an interval $\mathrm{f}_{0} \pm \varepsilon$ :

$\mathrm{s}_{22}^{\mathrm{A}} \cdot \mathrm{s}_{11}^{\mathrm{C}} \approx \mathrm{s}_{22}^{\mathrm{A}}\left(\mathrm{f}_{0}\right) \cdot \mathrm{s}_{11}^{\mathrm{C}}\left(\mathrm{f}_{0}\right)=\mathrm{A}$

where

$\mathrm{A}=|\mathrm{A}| \mathrm{e}^{\mathrm{j} \Phi_{\mathrm{A}}} \in \mathrm{C},|\mathrm{A}|<1$

In this case, $\left|\mathrm{s}_{21}\right|$ can be expressed as follows:

$\left|\mathrm{s}_{21}\right|=\left|\mathrm{s}_{21}^{\mathrm{A}} \cdot \mathrm{s}_{21}^{\mathrm{C}}\right| \cdot \mathrm{U}(\theta)$

where

$$
\mathrm{U}(\theta)=\frac{1}{\left|1-\mathrm{A} \cdot \mathrm{e}^{-\mathrm{j} 2 \theta}\right|}=\frac{1}{|1-| \mathrm{A} \cdot \mathrm{e}^{-\mathrm{j}\left(2 \theta-\Phi_{\mathrm{A}}\right)} \mid}
$$

$\mathrm{U}(\theta)$ is a periodic function with relative maximum and minimum points located at:

$$
\left\{\begin{array}{c}
\theta_{\max }=\frac{\Phi_{\mathrm{A}} \pm 2 \pi \mathrm{k}}{2} \\
\theta_{\text {min }}=\frac{\Phi_{\mathrm{A}}+\pi \pm 2 \pi \mathrm{k}}{2}
\end{array} \mathrm{k}=0,1,2, \ldots\right.
$$


Using (13), it is possible to express $\mathrm{U}(\theta)$ as a function of frequency, $\mathrm{U}_{1}(\mathrm{f})$ :

$$
\mathrm{U}(\theta)=\mathrm{U}\left(\frac{2 \pi \sqrt{\varepsilon_{\text {eff }}} \cdot 1}{\mathrm{c}} \cdot \mathrm{f}\right)=\mathrm{U}_{1}(\mathrm{f})
$$

At this point, the problem reduces to finding the electrical length, $\theta_{\max }$, that produces a relative maximum at a frequency $f_{\max } \geq f_{2}$ so that the slope of $\left|s_{21}{ }^{A} \cdot s_{21}{ }^{C}\right|$ (the transistors rolloff) can be compensated with the $U_{1}(\mathrm{f})$ positive slope over the operation bandwidth. Setting A to $\mathrm{f}_{\max }$ :

$\mathrm{A}=\mathrm{s}_{22}^{\mathrm{A}}\left(\mathrm{f}_{\max }\right) \mathrm{s}_{11}^{\mathrm{C}}\left(\mathrm{f}_{\max }\right)$

and substituting (20) into (18), we obtain the possible values of $\theta_{\max }$ :

$\theta_{\text {max }}=\frac{\Phi\left\langle\mathrm{s}_{22}^{\mathrm{A}}\left(\mathrm{f}_{\max }\right)\right\rangle+\Phi\left\langle\mathrm{s}_{11}^{\mathrm{C}}\left(\mathrm{f}_{\max }\right)\right\rangle \pm 2 \pi \mathrm{k}}{2}$

We will choose the shortest transmission line, that is, the solution with $\mathrm{k}=0$. In the case where the $\mathrm{U}_{1}(\mathrm{f})$ required slope cannot be synthesized with just the $f_{\max }$ parameter, it is possible to add a degree of freedom with the transmission line characteristic impedance, $\mathrm{Z}$, which can be different from $Z_{0}$. Choosing the appropriate value of $\mathrm{f}_{\max }$ (and $\mathrm{Z}$ when necessary), it is possible to equalize the $s_{21}$ module. To equalize the MAG, the optimum $\mathrm{f}_{\max }$ will be slightly different because of the approximations made previously. However, this analysis provides a value that is close to the optimum, which can be obtained using an easy optimization procedure that consists of sweeping $\theta$ in a short interval around the calculated $\theta_{\max }$ and testing for the best MAG flatness.

\section{APPLICATION}

In order to prove the efficacy of the described technique, we have implemented a high gain L-band amplifier for the COMS [8] communication satellite. At the outset, a structure with six conventional single-transistor stages was proposed. For each stage, a $13.5 \mathrm{~dB}$ gain, with less than $0.015 \mathrm{~dB}$ variation over a $7 \mathrm{MHz}$ bandwidth $(1.691-1.698 \mathrm{GHz})$, was specified. Unconditional stability over all frequencies was also required.

\section{Technology}

The amplifier is based on microstrip technology, using the Epsilam-10 substrate. Epsilam-10 characteristics are similar to those of the TMM10i substrate, which is qualified for use in space and will be used in the final circuits. The active elements are two Infineon BFY450 bipolar transistors. All the lumped components are qualified for use in space.

\section{Conventional Design}

In a conventional design, every stage is a single-transistor stage with simultaneous matching networks, as shown in Fig. (2). Complex conjugate match entails that reflections are minimized, and, therefore, the transducer power gain corresponds to the MAG. The transistor must be unconditionally stable, or MAG does not exist.

In our case, the BFY450 bipolar transistor is unconditionally stable above $1 \mathrm{GHz}$. Therefore, the MAG exits over the operation bandwidth, as represented in Fig. (3). Note that, with a conventional design, it is not possible to achieve the specified gain flatness (less than a $0.015 \mathrm{~dB}$ variation). So, a new structure consisting of three two-transistor stages, with the described equalization technique, was chosen.

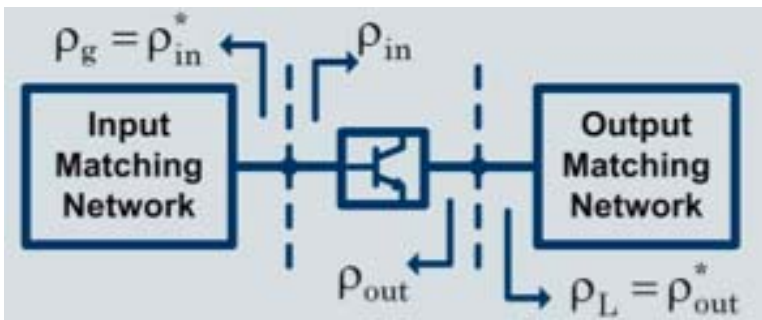

Fig. (2). Conventional design diagram.

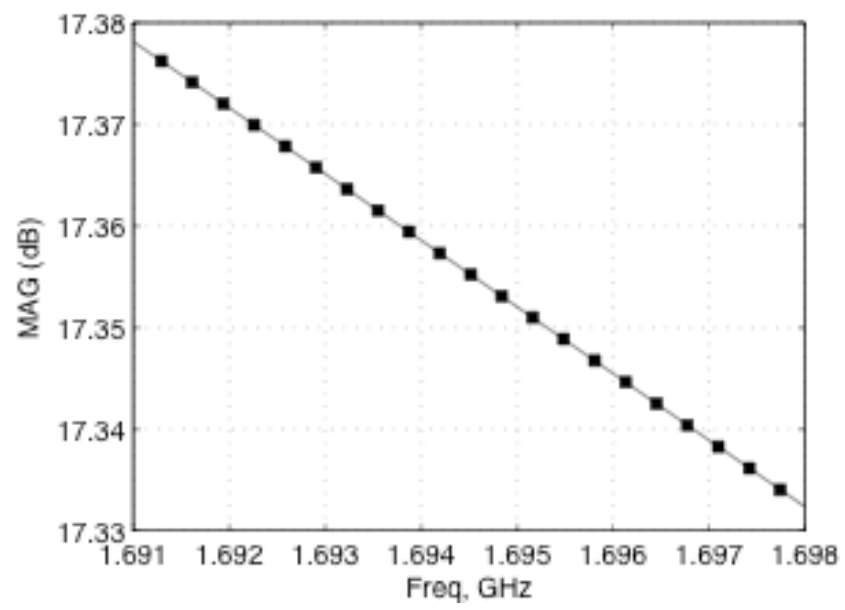

Fig. (3). Conventional design MAG.

\section{Technique Application: General Scheme}

The block diagram of each stage is shown in Fig. (4).

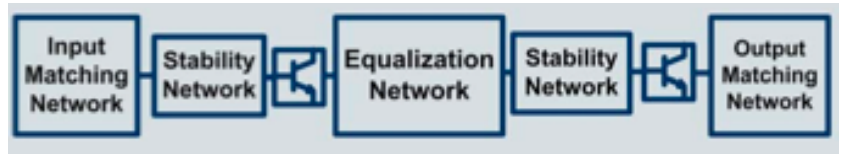

Fig. (4). Amplification stage block diagram.

We have developed two prototypes: one for the first and second stages, which will be called the intermediate stage, and another for the last stage, called the output stage. The block diagram is the same in both cases. The only difference is the polarization point, which is higher in the output stage to achieve the accurate $1 \mathrm{~dB}$ compression point.

\section{Equalization Network}

The described equalization technique leads to an $\mathrm{f}_{\max }=$ $1.7 \mathrm{GHz}$, which corresponds to $\theta_{\max }=173^{\circ}$. The amplifier microstrip layout was designed (including the bias, stability and matching networks) and implemented in a circuit simulator (Advanced Design System, ADS). After an easy optimization process, the final electrical length was set to $\theta_{\max }=$ $180^{\circ}$. Fig. (5) shows, over the operation bandwidth, both simulated cases: the transistor-line-transistor MAG, with a 
$173^{\circ}$ ideal transmission line, and the final designed amplifier response, including all parasitics.

We have analyzed the consequences of introducing the transmission line in other parameters of the circuit. We have checked that, besides the MAG equalization, the structure leads to relative minima in the input and output simultaneous matching coefficients. This behavior is shown in Fig. (6) for different electrical length values of an ideal transmission line. This means that the matching networks will be easier to synthesize, that they will be smaller, and that they will have weaker frequency dependence. Then, the $\theta_{\max }$ optimum value can be selected with a trade-off between maximum flatness and smallest simultaneous matching coefficients. This tradeoff will depend on the strictness of the specifications, which will determine if it is possible to renounce flatness in exchange for a better match. In our case, a $180^{\circ}$ electrical length, which provides the best flatness, was chosen.

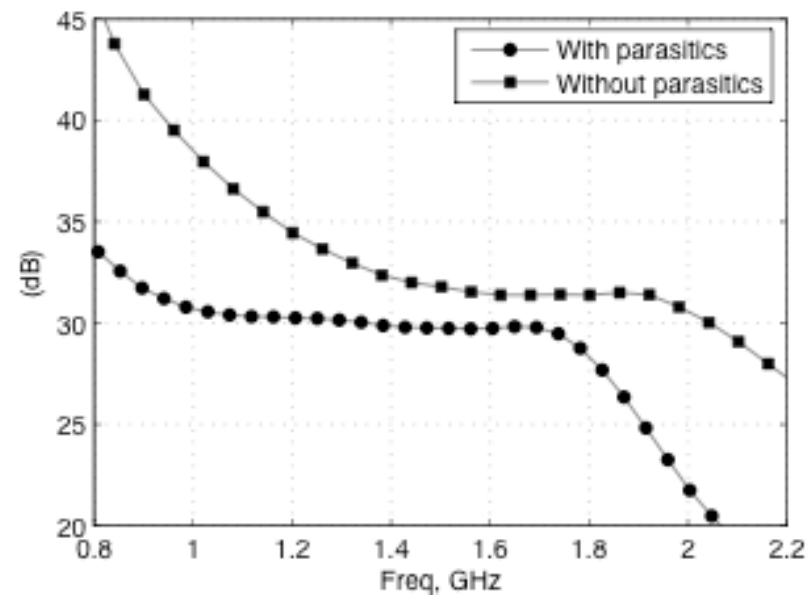

Fig. (5). Simulated ideal and real responses.

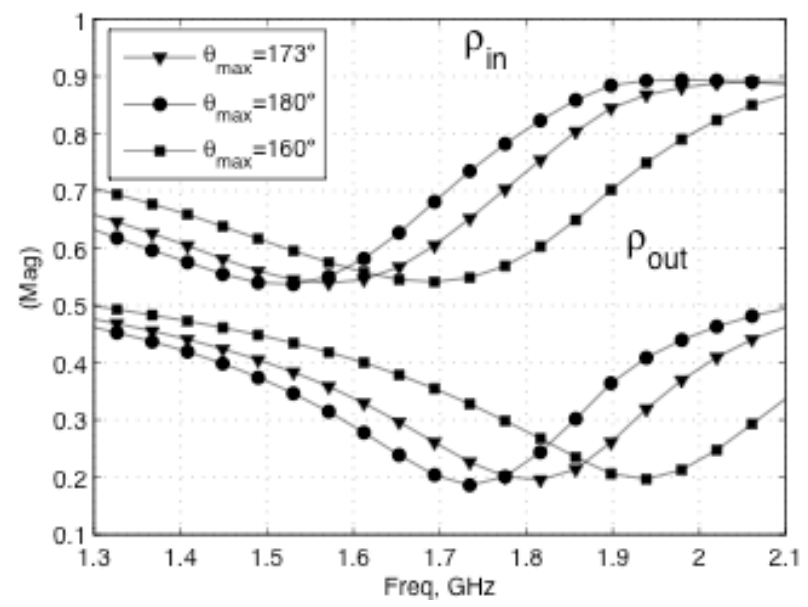

Fig. (6). Transistor-line-transistor simultaneous matching coefficients.

\section{Stability Networks}

Every transistor includes an input stability network to ensure unconditional stability. It is a frequency selective network, which means that it has only influence at low frequencies and is transparent over the operation bandwidth.
The network guarantees unconditional stability at low frequencies, where the transistor is conditionally stable, and it does not introduce attenuation at the band of interest. The network consists of a RC-parallel circuit.

\section{Matching Networks}

The input and output matching networks are synthesized with stubs [10]. As commented above, these networks are smaller and easier to implement than in the conventional design due to the introduction of the transmission line.

\section{Measurements}

The two built prototype layouts, intermediate stage and output stage, are shown in Fig. (7).

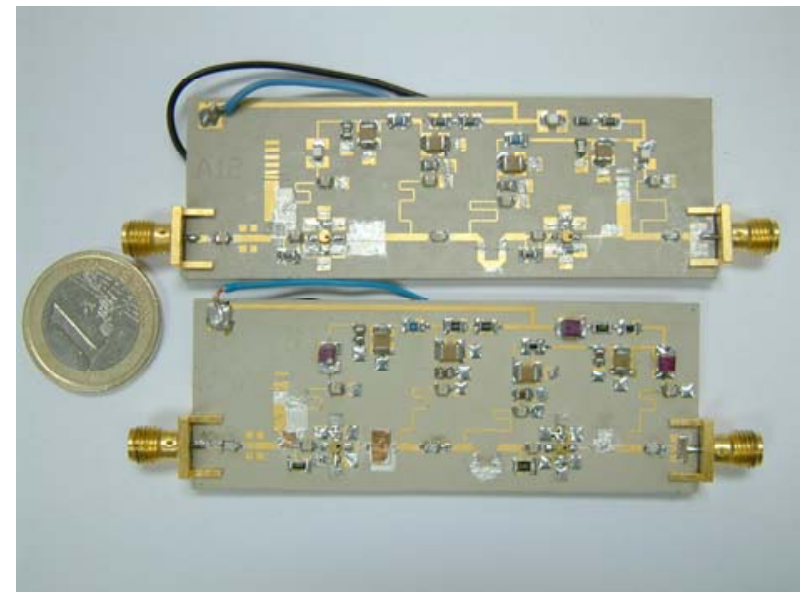

Fig. (7). Prototype layout.

The measured responses are similar in both prototypes, so we present only the results of the intermediate stage prototype.

The measured response from 0 to $1.8 \mathrm{GHz}$ is represented in Fig. (8). We observe that the $350 \mathrm{MHz}$ frequency, which corresponds to the local oscillator, is filtered. This is achieved with the appropriate polarization blok capacity values, which produce a resonance over the local oscillator frequency.

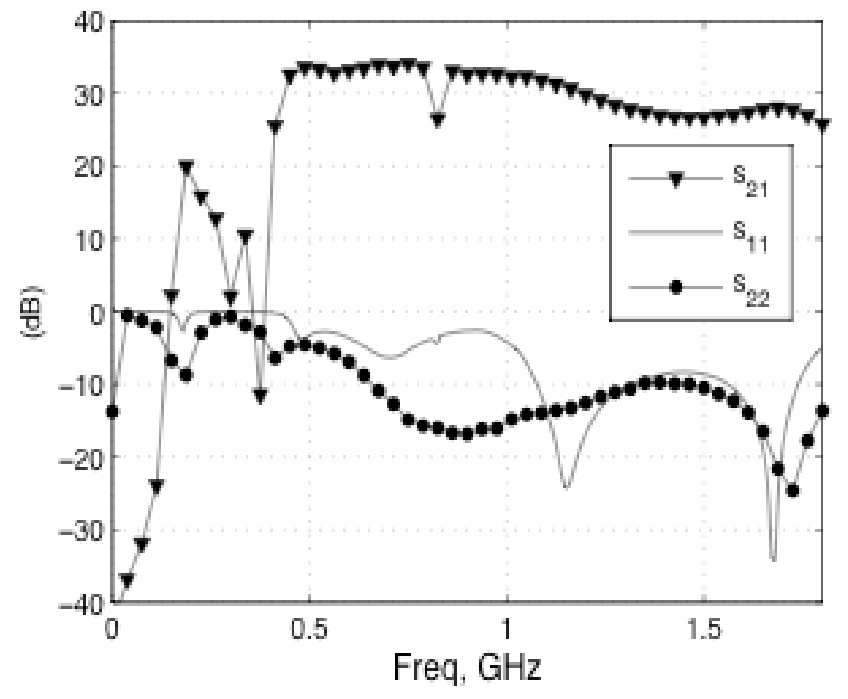

Fig. (8). Full band prototype measured response. 
The measured response in a narrow band is presented in Fig. (9). Over the operation bandwidth $(1.691-1.698 \mathrm{GHz})$, a $0.02 \mathrm{~dB}$ gain variation has been achieved, in addition to input and output matching better than $20 \mathrm{~dB}$.

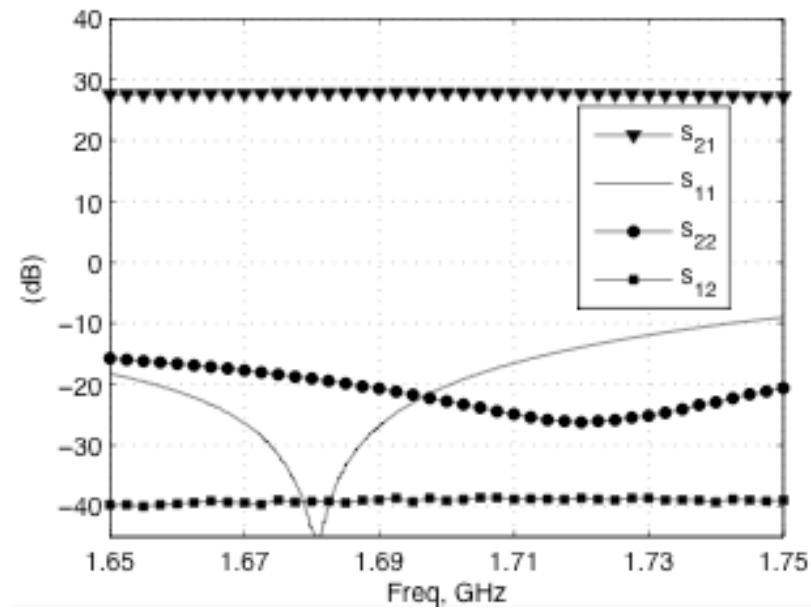

Fig. (9). Narrow band prototype measured response.

\section{CONCLUSIONS}

In this paper we have described a new MAG equalization technique for microwave amplifiers. The design is straightforward and provides excellent results. In addition to a very flat response, the method involves another important advantage. It improves the simultaneous matching coefficients, leading to simpler and smaller matching networks.

The technique has been validated using a high gain $\mathrm{L}$ band amplifier for a communications satellite, which is working at the moment.

\section{ACKNOWLEDGEMENTS}

This work has been supported by Alcatel Alenia Sapace España and the Spanish National Board of Scientific and Technological Research (CICYT), under project contract TEC2005-07010-C02.

\section{REFERENCES}

[1] T. Ha Tri, "Solid-State Microwave Amplifier Design”, GTE International Systems Corporation, John Wiley \& Sons, 1981, pp. 6380.

[2] O. Pitzalis, Jr., R.A. Gilson, "Tables of impedance matching networks which approximate prescribed attenuation versus frequency slopes", IEEE Trans. Microw. Theory Tech., vol. MTT-19, pp. 381-386, Apr. 1971.

[3] W.H. Ku, "Optimum gain-bandwidth limitations of transistor amplifiers as reactively constrained active two-port networks", IEEE Trans. Circuits Syst., vol. CAS-22, pp.523-533, June 1975.

[4] H.J. Carlin, "A New Method of brad-Band Equalization Applied to Microwave Amplifiers", IEEE Trans. Microw. Theory Tech., vol. MTT-27, no. 2, Feb. 1979.

[5] Mellor, D.J.; Linvill, J.G, "Synthesis of Interstage Networks of Prescribed Gain Versus Frequency Slopes", IEEE Trans. Microw. Theory Tech., vol. 23, pp. 1013-1020, Dec. 1975.

[6] R. Levy, "Design considerations for lumped-element microwave filters", Microw. J., vol. 31, pp. 183-192, Feb. 1988.

[7] I. C. Hunter, L. Billonet, B. Jarry, and P. Guillon, "Microwave filters-applications and technology," IEEE Trans. Microwave Theory Tech., vol. Mar. pp. 794-805, 2002.

[8] Herbert J. Kramer, "Observation of the Earth and Its Environment: Survey of Missions and Sensors", Springer Verlang. Available in http://directory.eoportal.org/pres_COMS1CommunicationOceanan dMeteorologicalSatellite1.html. $10^{\text {th }}$ Dec. 2007.

[9] David M. Pozar, "Microwave Engineering", John Wiley and Sons, Inc., Second Edition, pp. 606-627, 1998.

[10] Robert E. Collin, "Foundations for Microwave Engineering", McGraw-Hill, 1992, pp. 308-312.

(C) Morena-Álvarez-Palencia et al.; Licensee Bentham Open .

This is an open access article distributed under the terms of the Creative Commons Attribution License (http://creativecommons.org/licenses/by/2.5/), which permits unrestrictive use, distribution, and reproduction in any medium, provided the original work is properly cited. 